\title{
Cardiac remodelling
}

Cardiac remodelling refers to intrinsic alterations of the shape and size of the heart and its ultrastructure in response to haemodynamic and non-haemodynamic influences. The observed alterations should be independent of the changes that may be secondary to loading conditions at the time of measurement. How can we identify when remodelling in response to physiological and pathological demands becomes maladaptive?

\section{Physiological and pathological cardiac remodelling}

The term "remodelling" is commonly used to refer to adverse structural changes which occur in the ventricles. Consequently it is assumed that ventricular remodelling should be vigorously prevented or reversed in all cases. However, the term "remodelling" itself is neutral, and it is important to recognise that some forms of remodelling are adaptive, and hence beneficial to the function of the heart. To explore this concept further it is helpful to subdivide remodelling into physiological and pathological processes.

With the advent of better cardiac imaging techniques, it is not difficult to measure and identify alterations in the three dimensional structure of the heart. It is therefore tempting to adopt the more simplistic approach of classifying all observable left ventricular dilatation or hypertrophy as being pathological and therefore requiring treatment. The true challenge is in fact to distinguish which aspect of the remodelling is physiologically compensatory and therefore beneficial, and which is pathological and would benefit from treatment. By way of example, an athlete would be upset if he discovered that he was no longer competitive because unnecessary intervention had made his physiological cardiac hypertrophy regress.

Exercise training based on isotonic endurance exercise results in volume overloaded eccentric hypertrophy of the left ventricle, ${ }^{1}$ and the more accomplished the athletes the greater are the left ventricular end diastolic volumes. ${ }^{2}$ Remodelling of the heart occurs to ensure that large stroke volumes can be delivered during extreme exertion. Because each sarcomere has a maximum shortening distance, the stroke volume can be increased by increasing the number of in-series sarcomeres. The isometric resistance (for example, weight lifting) or power type of training results in pressure overloaded concentric hypertrophy of the left ventricle. ${ }^{3}$ Remodelling of the heart occurs so that higher intraventricular pressures can be generated. Since each myofibril has a limited capacity to develop tension, greater wall tension and intraventricular pressure can be generated by increasing the number of in-parallel myofibrils and the wall thickness. These remodelling processes, leading to ventricular dilatation and hypertrophy, are adaptive mechanisms to enhance cardiac pumping capability.

Pathological remodelling arises from structural and ultrastructural abnormalities, and results in functional impairment. Cardiomyocyte necrosis (secondary to infarction, myocarditis, cardiomyopathy, or cardiotoxicity) is the commonest cause. After this initiating pathological event the heart undergoes repair and remodelling that are compensatory. The necrotic myocytes are removed and replaced with collagen, the adjacent viable myocytes undergo hypertrophy, and the ventricle dilates. Treatment should be directed at preventing the pathological event that initiates the change and not at the subsequent physiological compensation.

Dilatation of the left ventricle is generally perceived to be detrimental, irrespective of the events initiating the process. To test whether this concept is correct, we can perform a thought experiment. Suppose that after a large myocardial infarction the heart was enclosed in a moulded steel case. Such protection would prevent the effects of volume overload, but would it enhance cardiac function? The answer must be no, because the heart would be less able to maintain adequate stroke volumes, especially during exercise. Thus it is not the dilatation itself that needs to be dealt with, but rather the factors precipitating the adaptive dilatation.

\section{Cardiac remodelling after myocardial infarction}

The most challenging aspect of our understanding of cardiac remodelling after myocardial infarction is how to explain the negative trend seen in the CONSENSUS II study ${ }^{4}$ which was stopped prematurely by the Safety Monitoring Committee "because of concerns about safety", ${ }^{5}$ and the contrasting positive beneficial survival effects of ACE inhibitors in the SAVE and AIRE studies. ${ }^{67}$ In the CONSENSUS II study, intravenous enalaprilat was given immediately after acute infarction to unselected patients, and it produced a trend towards harm. Even more surprisingly, the excess deaths appeared to result from a worsening of mechanical function. The SAVE and AIRE trials chose to treat only patients with identifiable left ventricular dysfunction after infarction (radionuclide left ventricular ejection fraction $\leqslant 40 \%$ in SAVE and clinical left ventricular failure in AIRE) with delayed introduction of the drug.

From animal experiments it is clear that early introduction of ACE inhibitors after myocardial infarction may cause harm, presumably by impeding the repair and compensatory processes. ${ }^{89}$ In patients the sympathetic and renin-angiotensin system, both circulating and localised, are activated after infarction, ${ }^{1011}$ but they are activated for longer if failure is present. ${ }^{12} 13$ These systems apparently play a major part in stimulating replacement fibrosis, angiogenesis, and compensatory hypertrophy of the viable myocardium. Formation of strong scar tissue is particularly important after large myocardial infarctions. These processes occur early after infarction, and their inhibition may render the heart less well adapted to the initial damage. Delayed introduction of ACE inhibitor therapy may avoid these detrimental effects, and may be one reason why the SAVE and AIRE studies, unlike CONSENSUS II, showed a survival benefit. 
After a sizeable myocardial infarction, dilatation of the left ventricle occurs, initially as a compensatory mechanism to maintain cardiac output and stroke volume during exercise. ${ }^{14}$ Subsequent progressive dilatation, especially after a year, results in worsening of cardiac reserve. The "mechanism of deteriorating function in regions with initially normal wall motion remains unclear". ${ }^{14}$

Histological examination of viable non-infarcted myocardium in patients reveals extensive replacement fibrosis, ${ }^{15} 16$ which implies that there has been progressive scattered myocyte loss in the non-infarcted myocardium. Both catecholamines and angiotensin are also known to be cardiotoxic in pathophysiological concentrations, and may therefore cause diffuse cumulative cardiomyocyte loss in the viable myocardial regions. ${ }^{17-19}$ Every myocyte death triggers compensatory hypertrophy and replacement fibrosis, and these cumulatively trigger compensatory ventricular dilatation. It is important to note that it is not progressive dilatation and hypertrophy in themselves that are harmful, but the continuing myocyte loss. Prevention of continuing myocardial injury secondary to activation of sympathetic and renin-angiotensin systems may be achieved by ACE and $\beta$ adrenoceptor inhibition. This would explain why patients with clinical failure after myocardial infarction are the ones most likely to benefit from ACE inhibition ${ }^{67}$ and $\beta$ blockade. ${ }^{20} 21$

It is the loss of cardiac myocytes, be it through infarct extension, reinfarction, or necrosis induced by excessive catecholamines and angiotensin II, that needs to be prevented. Successful prevention of myocyte loss would prevent ventricular dilatation. Myocardial protection, without compromising the natural reparative processes, should be the objective of therapeutic remodelling after extensive myocardial infarction.

Therapeutic remodelling: how to evaluate efficacy? Much effort has been expended in determining which is the best method to assess isolated aspects of cardiac function. However, when heart failure is treated, it is the overall function of the heart and how it interacts with the vasculature that should be evaluated. Any advances in therapeutic remodelling must be appraised by determining how well overall cardiac function can be preserved or improved by treatment.

There are many facets to the evaluation of cardiac function: diastolic $v$ systolic function, left ventricular hypertrophy $v$ its regression, dilatation $v$ its prevention. Improvement of one facet may be accompanied by deterioration in another, so that the overall function may be unchanged or worsened. Demonstration of an isolated piecemeal beneficial effect is insufficient evidence to support the conclusion that an overall benefit to the cardiac pump has occurred. It is always necessary to evaluate the overall cardiac pump function. 2223 For instance, any treatment purporting to be beneficial to the heart should ideally be shown either to preserve or improve cardiac pumping reserve. Because we are unable to distinguish between physiological and pathological remodelling after a morphological diagnosis, regression of ventricular hypertrophy or dilatation in an individual patient can only be beneficial if the cardiac reserve is improved after treatment. Measuring changes in cardiac reserve has advantages over other methods of assessment in that it takes into account the changes in both pressure and flow generating capacities, ${ }^{24}$ in systolic and diastolic dysfunction, and in function at rest and during maximal stress.

Institute of Cardiovascular Research,
Medical School, Leeds University

A S HALL

1 MacFarlane N, Northridge DB, Wright AR, Grant S, Dargie HJ. A comparative study of left ventricular structure and function in elite athletes. Br \& Sports Med 1991;25:45-8.

2 Crawford MH, Petru MA, Rabinowitz C. Effect of isotonic exercise training on left ventricular volume during upright exercise. Circulation 1985;72:1237-43.

3 Longhurst JC, Stebbins CL. The isometric athlete. Cardiol Clinics 1992; 10:281-94.

4 Swedberg $\mathrm{K}$, Held P, Kjekshus J, Rasmussen $\mathrm{K}$, Ryden $\mathrm{L}$, Wedel $\mathrm{H}$, on behalf of the CONSENSUS II Study Group. Effects of the early administration of enalapril on mortality in patients with acute myocardial infarction. Results of the Cooperative New Scandinavian Enalapril Survival Study II (CONSENSUS II). N Bnel Y Med 1992;327:678-84.

5 Furbers CD, Campbell RWF, Pitt B. ACE inhibitors after myocardial infarction (letter). $N$ Engl $Y$ Med 1993;328:967-8.

6 Pfeffer MA, Braunwald E, Moye LA, Basta L, Brown EJJr, Cuddy TE, et N al on behalf of the SAVE Investigators. Bffect of captopril on mortality and morbidity in patients with left ventricular dysfunction after myocar- $\omega$ dial infarction. Results of the survival and ventricular enlargement trial. $\mathrm{G}$ $N$ Engl Y Med 1992;327:669-77.

7 Acute Infarct Ramipril Bfficacy (AIRE) Study Investigators. Effect of ramipril on mortality and morbidity of survivors of acute myocardial infarction with clinical evidence of heart failure. Lancet 1993;342:821-8.

8 Schoemaker RG, Debets JM, Struyker Boudier HAJ, Smits JFM. Delayed but not immediate captopril therapy improves cardiac function in conscious rats, following myocardial infarction. $\Im$ Mol Cell Cardiol 1991;23:187-97.

9 van Krimpen C, Smits JFM, Cleutens JPM, Debets JM, Schoemaker RG, Struyker Boudier HAJ, Bosman FT, Daemen MJAP. DNA synthesis in the non-infarcted cardiac insterstitium after left coronary artery ligation in the rat: effects of captopril. I Mol Cell Candiol 1991;23: $1245-53$.

10 McDonald L, Baker C, Bray C, McDonald A \& Restieaux N (1969). Plasma catecholamines after cardiac infarction. Lancet 1969;11:1021-3.

11 Nabel E, Topol E, Galeana A, Ellis SG, Bates ER, Wern SW, et al. A randomized placebo-controlled trial of combined early intravenous captopril and recombinant tissue-type plasminogen activator therapy in acute myocardial infarction. $₹$ Am Coll Cardiol 1991;17:467-73.

12 Rouleau J, Moye L, de Champlain J, Klein M, Bichet D, Packer M, et al. Activation of neurohumoral systems following acute myocardial infarcActivation of neurohumoral systems foll

13 Sigurdsson $A$, Held $P$, Swedberg $K$. Short- and long-term neurohormonal activation following acute myocardial infarction. Am Heart Y 1993; 126:1068-76

14 Gaudron P, Eiles C, Kugler I, Ertl G. Progressive left ventricular dysfunction and remodelling after myocardial infarction. Potential mechanisms and early predictors. Circulation 1993;87:755-63.

15 Beltrami CA, Finato N, Rocco M, Feruglio GA, Puricelli C, Cigola E, Quaini F, Sonnenblick EH, Olivetti G \& Anversa P. Structural basis of end-stage failure in ischemic cardiomyopathy in humans. Circulation 1994;89:151-163.

16 Volders PGA, Willems IEMG, Cleutiens JPM, Arends J-W, Havenith MG, Daemen MJAP. Interstitial collagen is increased in the noninfarcted human myocardium after myocardial infarction. 9 Mol Cell Cardiol 1993;25:1317-23.

17 Benjamin IJ, Jalil JE, Tan LB, Cho K, Weber KT, Clark WA. D Isoproterenol-induced myocardial fibrosis in relation to myocyte necrosis. Circ Res 1989;65:657-70.

18 Tan LB, Jalil JE, Pick R, Janicki JS, Weber KT. Cardiac myocyte necrosis $N$ induced by angiotensin II. Circ Res 1991;69:1185-95.

19 Mann DL, Kent RL, Parsons B, Cooper G. Adrenergic effects on the $N$ biology of the adult mammalian cardiocyte. Circulation 1992;85: N

20 Furberg CD, Hawkins CM, Lichstein E, for the Beta-blocker Heart Attack Trial Study Group. Effect of propranolol in postinfarction patients with mechanical or electrical complications. Circulation 1984; patients with

21 Lichstein E, Hager WD, Gregory J, Fleiss J, Rolnitzky LM, Bigger JT, for the Multicenter Diltiazem Post-Infarction Research Group. Relation between beta-adrenergic blocker use, various correlates of left ventricular function and the chance of developing congestive heart failure. $9 \mathrm{Am}$ Coll Cardiol 1990;1649:1327-32.

22 Tan LB. Clinical and research implications of new concepts in the assessment of cardiac pumping performance in heart failure. Cardiovasc Res 1987;21:615-22.

23 Tan LB. Evaluation of cardiac dysfunction, cardiac reserve and inotropic response. Postgrad Med F 1991;67(suppl):10-20.

24 Shroff SG, Motz W. Left ventricular systolic resistance in rats with hypertension and hypertrophy. Am I Physiol 1989;257:H386-94. 